\title{
Endothelial progenitor cells promote tumor growth and progression by enhancing new vessel formation (Review)
}

\author{
XIN ZHAO ${ }^{1}$, HUAN-QIU LIU ${ }^{2}$, JI LI $^{2}$ and XIAO-LIANG LIU ${ }^{1}$ \\ ${ }^{1}$ Cancer Center; ${ }^{2}$ Department of Anesthesiology, The First Hospital of Jilin University, Changchun, Jilin 130021, P.R. China
}

Received April 29, 2015; Accepted June 2, 2016

DOI: $10.3892 / \mathrm{ol} .2016 .4733$

\begin{abstract}
Tumor growth and progression require new blood vessel formation to deliver nutrients and oxygen for further cell proliferation and to create a neovascular network exit for tumor cell metastasis. Endothelial progenitor cells (EPCs) are a bone marrow (BM)-derived stem cell population that circulates in the peripheral circulation and homes to the tumor bed to participate in new blood vessel formation. In addition to structural support to nascent vessels, these cells can also regulate the angiogenic process by paracrine secretion of a number of proangiogenic growth factors and cytokines, thus playing a crucial role in tumor neovascularization and development. Inhibition of EPC-mediated new vessel formation may be a promising therapeutic strategy in tumor treatment. EPC-mediated neovascularization is a complex process that includes multiple steps and requires a series of cytokines and modulators, thus understanding the underlying mechanisms may provide anti-neovasculogenesis targets that may be blocked for the prevention of tumor development. The present review stresses the process and contribution of EPCs to the formation of new blood vessels in solid tumors, in an attempt to gain an improved understanding of the underlying cellular and molecular mechanisms involved, and to provide a potential effective therapeutic target for cancer treatment.
\end{abstract}

Correspondence to: Dr Xiao-Liang Liu, Cancer Center, The First Hospital of Jilin University, 71 Xinmin Street, Changchun, Jilin 130021, P.R. China

E-mail: liuxiaoliangjiayi@163.com

Abbreviations: ECs, endothelial cells; EPCs, endothelial progenitor cells; BM, bone marrow; VEGF, vascular endothelial growth factor; VEGFR-2, VEGF receptor-2; SDF-1, stromal cell-derived factor-1; G-CSF, granulocyte colony-stimulating factor; HIF-1, hypoxia-inducible factor-1

Key words: endothelial progenitor cells, neovascularization, tumor, vascular endothelial growth factor, stromal cell-derived factor-1

\section{Contents}

1. Introduction

2. Properties of EPCs

3. Tumor development

4. Association of EPCs with tumor neovascularization

5. EPCs in tumor vascularization

6. Anti-neovascularization

7. Conclusion

\section{Introduction}

Cancer remains a leading cause of mortality in humans due to the limitations of current treatment. Surgery, radiotherapy and chemotherapy are common methods of anticancer treatment. Despite significant developments in therapeutic strategies, cancer remains a major public health issue (1). The growth of early-stage tumors relies on the diffusion of oxygen and nutrients from the surrounding tissue, and under these conditions, tumor can grow to a size of $1-2 \mathrm{~mm}^{3}$. Further expansion of the tumor mass requires establishment of new blood vessels to support the increased metabolic demand (2). Tumor development depends upon the formation of new blood vessels to deliver oxygen and micronutrients, and to facilitate cancer metastasis into the systemic circulation (3). The formation of blood vessels occurs by two mechanisms: Angiogenesis and vasculogenesis. Angiogenesis is the process via which new vessel formation occurs through proliferation and migration of existing neighboring endothelial cells (ECs) $(4,5)$. It was previously generally believed to be the only mechanism responsible for new blood vessel formation during postnatal life and the exclusive result of the sprouting of new vessels to support tumor development. This traditional concept of blood vessel formation has been challenged by the identification of the bone marrow (BM)-derived cell population endothelial progenitor cells (EPCs) that could be recruited and differentiate into mature ECs in injured endothelium (6). Moreover, EPCs can also secrete a series of cytokines to promote new vessel formation (7). EPCs have been reported to migrate actively to the tumor bed and incorporate directly in the neovasculature with high specificity (8-10). Thus, EPCs that mediate neovascularization may be crucial contributors to the growth and spread of cancer, and have become an important promising target for antineoplastic therapies in a variety of solid tumors $(2,11,12)$. 
EPC-mediated neovascularization is a multiple step process, in which numerous cytokines and modulators are involved to regulate cell mobilization, recruitment and incorporation into the endothelium (13). Although the contribution of EPCs to new vessel formation has previously been established, the underlying mechanisms remain unclear and require further study, which may provide a potential target in therapeutic management by blocking the process and signal pathways involved in EPC-mediated tumor neovessel formation.

\section{Properties of EPCs}

EPCs are a BM-derived cell population that circulates in the peripheral circulation and homes to the sites of injured vessels to participate in new blood vessel formation under physiopathological conditions (6). Vascular endothelial growth factor receptor-2 (VEGFR-2) and cluster of differentiation (CD)34 were initially described as specific expression markers of the cells; however, these markers are also expressed on hemangioblast and hematopoietic progenitors, as well as certain mature ECs (6). Putative EPCs encompass different cell populations that all originate from the hemangioblast overlap, phenotypically as well as functionally, and present in different stages of endothelial differentiation in the peripheral blood. Recently, an array of biomarkers has been used to characterize the putative EPCs, including CD34, CD133, CD31, VEGFR-2, von Willebrand factor (vWF), CD144, Tie2, CD117, CD62E and CD45 (14-18). The glycosylated form of the CD133 protein has been accepted as a more appropriate marker for immature progenitor cells, since it is expressed on immature stem cells, but not on mature ECs $(19,20)$. Thus, CD133 ${ }^{+} /$VEGFR $^{2}{ }^{+}$ cells more likely reflect immature progenitor cells localized mainly in the $\mathrm{BM}$, whereas $\mathrm{AC} 133 \% \mathrm{CD} 34^{+} / \mathrm{VEGFR}-2^{+}$cells may represent more mature cells that are limited in their proliferative capacity (21). There are two main types of EPCs, early and late EPCs, which are isolated by different culture methods $(15,16)$. Early EPCs obtained from short-term blood sample cultures possess numerous endothelial characteristics, such as harboring markers of CD31, CD133, CD34 and VEGFR-2 (2), while late EPCs express VE-cadherin and vWF, as well as endothelial markers such as CD31, CD133, CD34 and VEGFR-2 (22). Mounting evidence has suggested that early and late EPCs play a critical role in postnatal angiogenesis and vasculogenesis under a number of pathological conditions, including myocardial ischemia and infarction, wound healing, atherosclerosis, limb ischemia and tumor development $(8,23-29)$. Therefore, in the treatment of diseases such as solid tumors, EPCs have been considered as potential targets that are closely associated with neovascularization (30).

\section{Tumor development}

Tumors arise from several sequential genetic mutations in DNA that result in the cell deregulation of normal growth control mechanisms and uncontrolled proliferation. Eventually, these mutated cells expand to become a cell mass that is able to obtain adequate nutrients and oxygen via the diffusion from surrounding tissues to support growth at an early stage (31). Once cell deposits reach a size of 1-2 $\mathrm{mm}^{3}$, expansion of the tumor requires nascent vasculature to deliver nutrients and oxygen for further cell proliferation (32). In addition to delivering oxygen and micronutrients to the tumor mass, the ECs promote tumor growth via paracrine growth and survival signals (33-35). Tumor angiogenesis can also facilitate cancer metastasis by allowing cells to exit through the neovascular network into the systemic circulation (36). The production of new blood vessels from an existing vascular bed is known as angiogenesis. However, recent attention has focused on tumor-associated vasculogenesis that occurs through mature ECs via the proliferation and differentiation of BM-derived EPCs. Accumulating data indicate that EPCs provide not only structural support to nascent vessels (37-39), but that they also regulate the angiogenic process via paracrine secretion of a number of proangiogenic growth factors (2). Through these mechanisms, EPCs have a dual role in tumor development. Thus EPCs may be an essential component in cancer growth and progression, and the inhibition of EPC-mediated neovascularization may efficiently block tumor development.

\section{Association of EPCs with tumor neovascularization}

EPCs were first described as a subtype of stem cells that gave rise to mature ECs in culture and were able to incorporate themselves into sites of active neovascularization in animal models (6). The cells were then extensively studied regarding their role in neovascularization. Accumulating data has confirmed that early and late EPCs participate in the process of new vessel formation under a wide range of physiopathological conditions. Early EPCs promote angiogenesis by secreting a series of growth factors and cytokines, such as VEGF, stromal cell-derived factor-1 (SDF-1), granulocyte colony-stimulating factor (G-CSF) and insulin-like growth factor 1, which enhance EC proliferation and survival, and direct endogenous progenitor cell recruitment into nascent vessel sites $(6,40)$. Late EPCs contribute to vasculogenesis by providing structural support via differentiation into mature ECs (16). Late EPCs can also promote angiogenesis by the secretion of numerous cytokines (7). The contribution of EPCs in postnatal endothelial repair and vasculogenesis has been documented in physiological and pathological conditions, such as myocardial ischemia (24), limb ischemia (27), ischemic stroke (26), wound healing (28) and tumor vascularization (41). Accumulating evidence has suggested that the number of circulating EPCs is elevated in a wide range of cancer types, such as glioma, non-small cell lung cancer, myeloid leukemia, hepatocellular carcinoma, colorectal cancer, lymphoma and breast cancer $(42,43)$. EPCs are considered to be a key contributor to the new vessel formation of a tumor during its development $(2,44)$. Initial evidence of the involvement of EPCs in tumor neovessels was discovered in $\mathrm{Id}^{+} / \mathrm{Id} 3 \%$ tumor mouse models (41). The study demonstrated that the defection in the recruitment of BM-derived endothelial precursor cells blocks tumor angiogenesis and growth, and that this could be reversed by the transplantation of circulatory EPCs. Significantly, the donor-derived cells were detected throughout the tumor neovessels in the animal cancer models (41). Subsequent studies showed that the blockage of EPC mobilization from the BM or recruitment to the tumor bed can result in significant inhibition of tumor neovasculogenesis and growth $(45,46)$. These data demonstrate that EPCs contribute to new vessel formation in tumor development. 


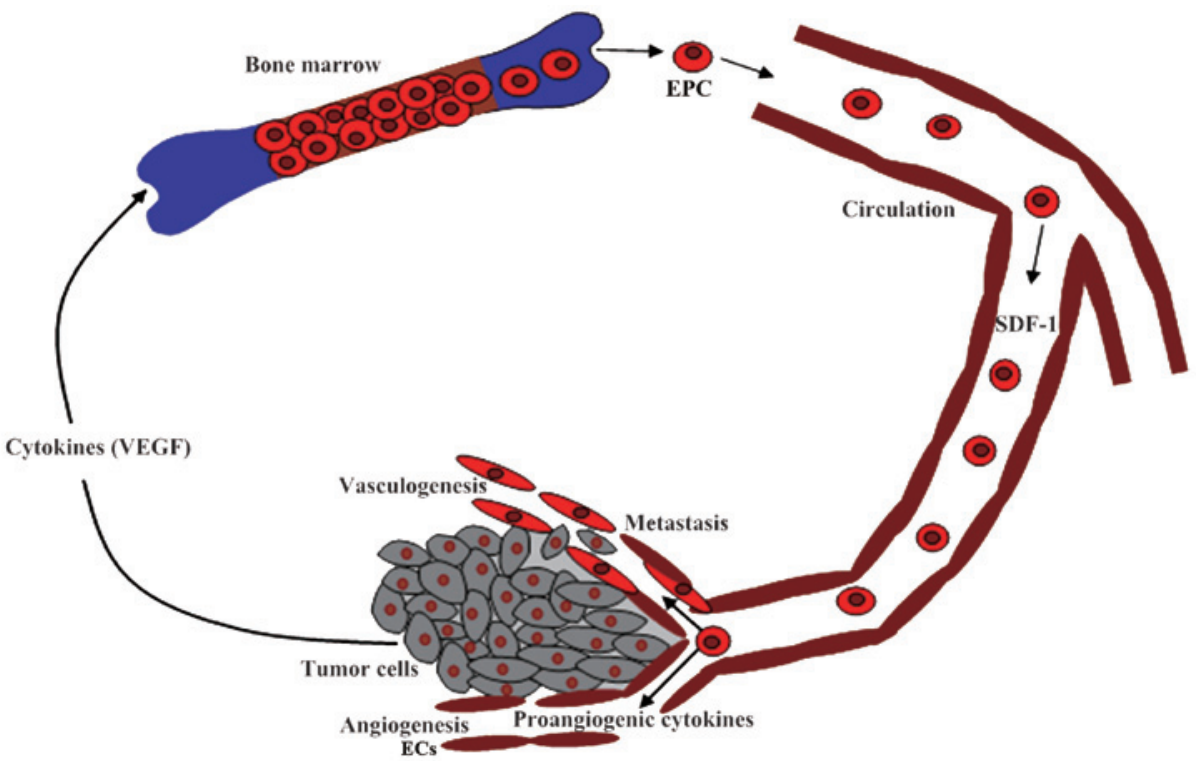

Figure 1. EPCs are mobilized from the BM into the circulation and home to the tumor bed to participate in neovascularization. Malignant tumor growth results in neoplastic tissue hypoxia that induces VEGF production. This production of VEGF promotes the mobilization of BM-derived EPCs into the circulation. The circulating EPCs move following the SDF-1 gradients towards the tumor bed, subsequently incorporating themselves into nascent vessels, differentiating into mature endothelial cells to provide structural support and releasing a series of cytokines to promote angiogenesis. VEGF, vascular endothelial growth factor; BM, bone marrow; EPCs, endothelial progenitor cells; SDF-1, stromal cell-derived factor-1.

\section{EPCs in tumor vascularization}

EPC-mediated neovascularization is a complex process, including EPC mobilization from the BM into the peripheral circulation, recruitment and adhesion to the sites of new vessel formation, incorporation into the intima to form de novo vessels, and paracrine support of the nascent microvasculature (Fig. 1). These events are controlled by multiple cytokines and modulators via different mechanisms (47).

Mobilization of EPCs from the BM into the circulation is the first step for EPC-mediated vasculogenesis. In normal conditions, the number of circulating EPCs is extremely low (15), and the majority of the cells reside in the niche within the $\mathrm{BM}$ via the interaction of the integrins expressed on these cells with stromal cells $(48,49)$.

Tumor vasculogenesis requires signaling between tumor cells and the EPCs residing in the BM, stimulating them to mobilize into the peripheral circulation, home to the tumor sites and invade the growing tumor (50). The process involves multiple steps that are regulated by a wide range of cytokines and chemokines. VEGF is a pleiotropic cytokine that has been implicated in the mobilization of VEGFR-2 ${ }^{+}$EPCs from the $\mathrm{BM}$, and VEGF gene transfer has been shown to augment circulating EPCs in humans $(51,52)$. VEGF is an angiogenic cytokine that is expressed in the tumor bed. The high levels of VEGF promote tumor vasculogenesis and progression by mobilizing BM-resident EPCs into the peripheral circulation, and enhance the recruitment of these cells to the tumor sites (51,53-55). VEGF mechanism in EPC-mediated neovascularization involves a number of enzyme and cytokines. VEGF activates BM nitric oxide (NO) synthase and promotes NO production. This NO interacts with matrix metalloproteinase-9, leading to the release of stem cell-active soluble kit ligand, which enhances VEGFR-2+ EPC mobility and stimulates cell mobilization from the $\mathrm{BM}$ into the peripheral circulation (56). VEGF has the ability to upregulate the levels of G-CSF, inducing the release of progenitor cells from the BM (57). G-CSF mechanisms in EPC mobilization are correlated with BM-neutrophil-released elastase and cathepsin G, which induce the proteolytic cleavage of vascular cell adhesion molecule-1, expressed by BM stromal cells, followed by progenitor cell mobilization (58). The CXC motif chemokine family is another well-known inducer of EPC mobilization. SDF-1 is the most well-characterized component of EPC mobilization and a effective chemokine in the adhesion and migration of the cells. The expansion of the tumor causes surrounding tissue hypoxia, which through elevated levels of hypoxia-inducible factor-1 (HIF-1), upregulates the responsive of chemokines such as SDF-1 and VEGF, and stimulates the release and recruitment of EPCs from the BM into the circulation $(52,59,60)$. Tumors can also produce chemokine (C-C motif) ligand (CCL)2 and CCL5, which are involved in EPC mobilization (61). In addition, the cells surrounding the tumor produce other factors to mobilize EPCs and recruit them to the tumor bed. Adiponectin, for example, is a peptide hormone secreted by adipocytes that has been shown to promote EPC numbers and mammary tumor growth (62-64).

The recruitment of EPCs from the circulation to the site of the tumor bed is an essential step for EPC-mediated new vessel formation in neoplasm growth and development. Tumor and ischemic tissues have the potential to direct EPCs from the circulation into vasculogenic sites in order to increase the number of sprouting vessels for the blood supply via secretion of cytokines, of which SDF-1 is the most potent $(65,66)$. SDF-1 functions as a major chemokine to direct various types of chemokine $\left(\mathrm{C}-\mathrm{X}-\mathrm{C}\right.$ motif) receptor $4(\mathrm{CXCR} 4)^{+}$cells to the tumor bed (65-69). In normal conditions, the levels of SDF-1 are low in the circulation, BM and other tissues (49). As a secretory protein, the level of SDF-1 is upregulated in the tumor microenvironment, where it can create a gradient 
between the peripheral blood and the tumor microenvironment, directing the migration of EPCs from the circulation into the tumor bed (30). The process requires HIF, a heterodimeric transcription factor sensitive to oxygen concentrations in tissues (70). Malignant tumor growth results in neoplastic tissue hypoxia, which then induces HIF production. The SDF-1 promoter contains HIF-1 binding sites, and the binding leads to SDF-1 production (66). There is an increasing amount of evidence suggesting that the overexpression of SDF-1 is closely associated with neovascularization by mediating the homing and retention of pro-vasculogenic stem cells to areas of new vessel formation $(49,71,72)$. Histological analysis in rat glioma and melanoma models revealed that the majority of implanted, magnetically-labeled cord blood-derived $\mathrm{AC} 133^{+}$ EPCs were expressed in peripheral regions of the tumor, and the high levels of HIF-1 and SDF-1 were also disturbed in regions, indicating a more hypoxic microenvironment. The studies also showed the incorporation of human $\mathrm{AC}^{3} 33^{+}$ cells into the tumor neovasculature upon immunofluorescent staining (73). In diabetes, a wound site is characterized by low levels of SDF-1 and delayed healing. This could be reversed by the administration of SDF-1 to improve the efficiency of EPC migration, consequently enhancing neovascularization and wound healing. This indicates the correlation of SDF-1 with the homing of EPCs to the neovessel and subsequently, EPC-mediated new vessel formation (74). The CXC/CXCR4 pathway pays a crucial role in these processes. SDF-1 is a member of the CXC chemokine family, which plays an important role in chemotaxis (71,72). SDF-1 exerts a chemoattractant role through binding with its receptor, CXCR4, expressed on the surface of EPCs. Blocking the SDF-1/CXCR4 pathway inhibits the ability of EPCs to home and their adhesion to the sites of ischemic tissues, indicating the involvement of the SDF-1/CXCR4 pathway in the process of EPC-mediated neovascularization $(75,76)$. The interaction of SDF-1 with CXCR4 activates multiple downstream targets, ultimately leading to cytoskeletal rearrangements, actin polymerization, polarization, pseudopodia formation and integrin-dependent adhesion to ECs (77).

EPC adhesion requires the molecular targets expressed by EPCs and by the angiogenic tissues that they home to (78). P selectin glycoprotein ligand-1 (PSGL-1) is a binding protein expressed on EPCs involved in cell adhesion; it is a major ligand of P-selectin and E-selectin expressed on ECs. The binding results in EPC transendothelial migration into the blood vessel wall where vascular remodeling is required (79). In the microenvironment of angiogenic sites, released SDF-1 may be vital in the modulation of this process via the SDF-1/CXCR4 pathway (80). The interaction of SDF-1 and EPC CXCR4 upregulates the expression of PSGL-1 on the EPC surface, leading to the adhesion and rolling of the cells to the blood vessel wall (Fig. 2). The adhesion of the EPCs to the endothelial monolayer is also strengthened by integrins, a type of cell adhesion molecule expressed on the cell surface (81). The interaction of integrins with intercellular adhesion molecule-1 and fibrinogen mediates the adhesion of the EPCs to active angiogenic sites and facilitates the cells transendothelial migration $(82,83)$. The release of high-mobility group box 1 by necrotic cells can also promote EPC adhesion to the sites of new vessel formation via the activation of $\beta 1$ - and

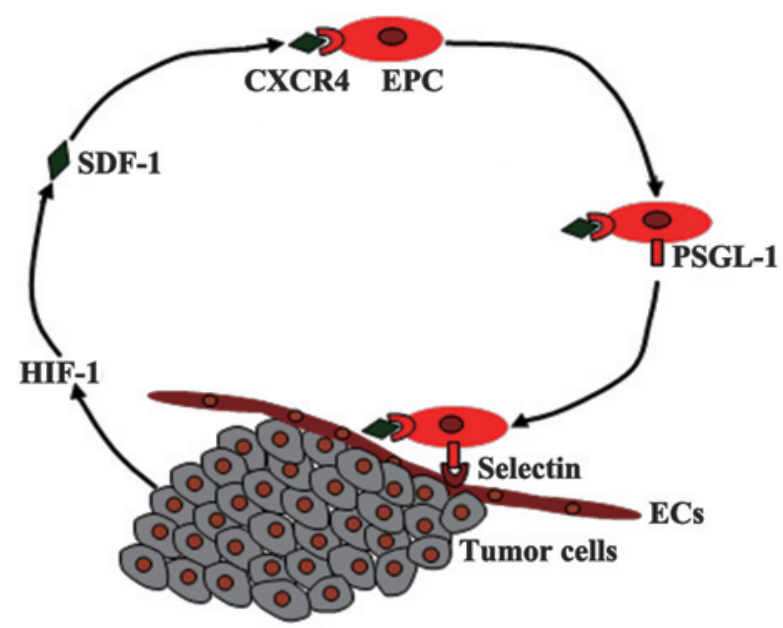

Figure 2. SDF-1 directs the circulating EPCs homing to the tumor bed. Tumor expansion causes surrounding tissue hypoxia, which through elevated levels of HIF-1 $\alpha$, upregulates the responsive of the chemokines to SDF-1 $\alpha$, a ligand of CXCR4. The interaction upregulates the PSGL-1 expression on the surface of the EPCs, leading to the adhsion and rolling of the cells to the blood vessel wall. HIF-1, hypoxia-inducible factor-1; SDF-1 $\alpha$, stromal cell-derived factor-1 $\alpha$; CXCR4, chemokine (C-X-C motif) receptor 4; PSGL-1, P selectin glycoprotein ligand-1; EPCs, endothelial progenitor cells; ECs, endothelial cells.

$\beta 2$-integrins $(84,85)$. This process is initiated by the activation of proangiogenic factors, such as VEGF, followed by the conversion of inactive enzyme plasminogen into the active serine protease plasmin and degradation of the extracellular matrix (86). In addition, upregulation of $\alpha 4$-integrin can also improve circulating progenitor cell invasion into the neovasculature and augment ischemic neovascularization $(87,88)$. Overall, the process of EPC-mediated neovascularization is complex, including multiple steps in which numerous cytokines and modulators are involved.

\section{Anti-neovascularization}

The human vascular system forms an intricate and dynamic network in the body for the delivery of oxygen and micronutrients to tissues, and for the removal of carbon dioxide and metabolic by-products. The system also exerts effects on adjacent nonvascular cells by secreting paracrine growth and survival signals (33). Pathological excessive neovascularization can promote the growth of diseased tissues, which can be observed in the majority of cancers $(89,90)$. Tumor progression depends largely on new vessel formation to deliver oxygen and nutrients for tumor growth, expansion and metastasis; thus inhibiting tumor neovascularization may be an effective treatment strategy for various solid cancer types. The first hypothesis stating that the inhibition of neovascularization may be an effective strategy in cancer treatment was proposed in 1971 (91). Subsequent studies in animal models indicated that anti-angiogenesis at an early stage could prevent tumor growth and development in a wide spectrum of cancers (92). Preclinical, clinical and epidemiological data have shown that the inhibition of angiogenesis achieves the prevention of tumor development $(93,94)$. A number of agents have been shown to exhibit effective antiangiogenic activities and exert 
preventative roles in the growth of a series of cancer types, including colorectal, renal, liver, lung, brain, pancreatic and neuroendocrine tumors, and multiple myeloma (95). It is now accepted that postnatal neovessel formation depends not only on angiogenesis, but also on vasculogenesis, which requires BM-derived EPC incorporation into the endothelium and differentiation into mature ECs to provide structural support to nascent vessels (96). Similarly, tumors obtain their vasculature through not only angiogenesis, but also through EPC-mediated vasculogenesis $(41,97)$. In addition to structural support to nascent vessels $(37,38)$, EPCs can also regulate the angiogenic process via the paracrine secretion of a number of proangiogenic growth factors and have a dual role in tumor development (30). Inhibiting EPC-mediated vasculogenesis, similar to anti-angiogenesis, may block tumor progression. This hypothesis is supported by studies that blocked EPC mobilization from BM or recruitment to the tumor bed, resulting in significant inhibition of tumor neovasculogenesis and growth $(45,46)$. Disruption of SDF-1/CXCR4 via the CXCR4 blocking antibody, for example, reduced the recruitment of BM-derived progenitor cells to the tumor bed and resulted in the inhibition of tumor growth in mouse models (98). A complete understanding of the mechanisms underlying EPC-mediated neovascularization is therefore required, as this may result in potential effective methods of cancer treatment.

\section{Conclusion}

EPC-mediated neovascularization may be an essential component of cancer grow th and development. In addition to providing structural support to nascent vessels in tumor expansion, EPCs can also promote tumor progression via independent vasculogenesis pathways. EPCs release a series of cytokines that exert effects on angiogenesis and vasculogenesis. The process of EPC-mediated neovascularization involves multiple steps, including cell mobilization, recruitment and adhesion to neovessel sites, and incorporation into the endothelium. Numerous cytokines are involved. Blockage of the process may reduce new vessel formation in tumors, followed by the blockage of tumor growth, invasion and metastasis. Thus, a comprehensive understanding of the mechanisms by which EPCs participate in neovascularization is required, which may provide potential targets in cancer treatment by blocking EPC-mediated tumor neovascularization.

\section{Acknowledgements}

This study was supported by the Natural Science Foundation for Young Scientists of Jilin Province, China (grant no. 20140520035JH) to L.X.L., "13th Five-Year" science and technology research of the Education Department of Jilin Province, China (grant no. 2016-483) to Z.X. and the Health and Family Planning Commission for Young Scientists of Jilin Province, China (grant no. 2015Q008) to L.X.L.

\section{References}

1. Global Burden of Disease Cancer Collaboration; Fitzmaurice C, Dicker D, Pain A, et al: The global burden of cancer 2013. JAMA Oncol 1: 505-527, 2015.
2. Janic B and Arbab AS: The role and therapeutic potential of endothelial progenitor cells in tumor neovascularization. Scientific World Journal 10: 1088-1099, 2010.

3. Kerbel RS: Tumor angiogenesis: Past, present and the near future. Carcinogenesis 21: 505-515, 2000.

4. Folkman J and Shing Y: Angiogenesis. J Biol Chem 267: 10931-10934, 1992.

5. Folkman J: Seminars in medicine of the Beth Israel Hospital, Boston. Clinical applications of research on angiogenesis. $\mathrm{N}$ Engl J Med 333: 1757-1763, 1995.

6. Asahara T, Murohara T, Sullivan A, Silver M, van der Zee R, Li T, Witzenbichler B, Schatteman G and Isner JM: Isolation of putative progenitor endothelial cells for angiogenesis. Science 275: 964-967, 1997.

7. MoubarikC,Guillet B, Youssef B,Codaccioni JL,Piercecchi MD, Sabatier F, Lionel P, Dou L, Foucault-Bertaud A, Velly L, et al: Transplanted late outgrowth endothelial progenitor cells as cell therapy product for stroke. Stem Cell Rev 7: 208-220, 2011.

8. Nolan DJ, Ciarrocchi A, Mellick AS, Jaggi JS, Bambino K, Gupta S, Heikamp E, McDevitt MR, Scheinberg DA, Benezra R and Mittal V: Bone marrow-derived endothelial progenitor cells are a major determinant of nascent tumor neovascularization. Genes Dev 21: 1546-1558, 2007.

9. Folkins C, Shaked Y, Man S, Tang T, Lee CR, Zhu Z, Hoffman RM and Kerbel RS: Glioma tumor stem-like cells promote tumor angiogenesis and vasculogenesis via vascular endothelial growth factor and stromal-derived factor 1 . Cancer Res 69: 7243-7251, 2009.

10. Zhang HR, Chen FL, Xu CP, Ping YF, Wang QL, Liang ZQ, Wang JM and Bian XW: Incorporation of endothelial progenitor cells into the neovasculature of malignant glioma xenograft. J Neurooncol 93: 165-174, 2009.

11. Chen X, Fang J, Wang S, Liu H, Du X, Chen J, Li X, Yang Y, Zhang B and Zhang W: A new mosaic pattern in glioma vascularization: Exogenous endothelial progenitor cells integrating into the vessels containing tumor-derived endothelial cells. Oncotarget 5: 1955-1968, 2014.

12. Russell JS and Brown JM: Circulating mouse Flk1 $1^{+} / \mathrm{c}-\mathrm{Kit}^{+} / \mathrm{CD} 45$ cells function as endothelial progenitors cells (EPCs) and stimulate the growth of human tumor xenografts. Mol Cancer 13: 177,2014

13. Lee PS and Poh KK: Endothelial progenitor cells in cardiovascular diseases. World J Stem Cells 6: 355-366, 2014.

14. Rouhl RP, van Oostenbrugge RJ, Damoiseaux J, Tervaert JW and Lodder J: Endothelial progenitor cell research in stroke: A potential shift in pathophysiological and therapeutical concepts. Stroke 39: 2158-2165, 2008.

15. Fadini GP, Losordo D and Dimmeler S: Critical reevaluation of endothelial progenitor cell phenotypes for therapeutic and diagnostic use. Circ Res 110: 624-637, 2012.

16. Hur J, Yoon CH, Kim HS, Choi JH, Kang HJ, Hwang KK, $\mathrm{Oh} \mathrm{BH}$, Lee MM and Park YB: Characterization of two types of endothelial progenitor cells and their different contributions to neovasculogenesis. Arterioscler Thromb Vasc Biol 24: 288-293, 2004.

17. Hristov M, Erl W and Weber PC: Endothelial progenitor cells: Mobilization, differentiation and homing. Arterioscler Thromb Vasc Biol 23: 1185-1189, 2003.

18. Walenta KL, Bettink S, Böhm M and Friedrich EB: Differential chemokine receptor expression regulates functional specialization of endothelial progenitor cell subpopulations. Basic Res Cardiol 106: 299-305, 2011.

19. Gehling UM, Ergün S, Schumacher U, Wagener C, Pantel K, Otte M, Schuch G, Schafhausen P, Mende T, Kilic N, et al: In vitro differentiation of endothelial cells from AC133-positive progenitor cells. Blood 95: 3106-3112, 2000.

20. Peichev M, Naiyer AJ, Pereira D, Zhu Z, Lane WJ, Williams M, Oz MC, Hicklin DJ, Witte L, Moore MA and Rafii S: Expression of VEGFR-2 and AC133 by circulating human CD34(+) cells identifies a population of functional endothelial precursors. Blood 95: 952-958, 2000.

21. Khakoo AY and Finkel T: Endothelial progenitor cells. Annu Rev Med 56: 79-101, 2005

22. Shantsila E, Watson T and Lip GY: Endothelial progenitor cells in cardiovascular disorders. J Am Coll Cardiol 49: 741-752, 2007.

23. Kawamoto A, Gwon HC, Iwaguro H, Yamaguchi JI, Uchida S, Masuda H, Silver M, Ma H, Kearney M, Isner JM and Asahara T: Therapeutic potential of ex vivo expanded endothelial progenitor cells for myocardial ischemia. Circulation 103: 634-637, 2001. 
24. Kawamoto A, Tkebuchava T, Yamaguchi J, Nishimura $\mathrm{H}$, Yoon YS, Milliken C, Uchida S, Masuo O, Iwaguro H, Ma H, et al: Intramyocardial transplantation of autologous endothelial progenitor cells for therapeutic neovascularization of myocardial ischemia. Circulation 107: 461-468, 2003.

25. Zhang ZG, Zhang L, Jiang Q and Chopp M: Bone marrow-derived endothelial progenitor cells participate in cerebral neovascularization after focal cerebral ischemia in the adult mouse. Circ Res 90: 284-288, 2002.

26. Fan Y, Shen F, Frenzel T, Zhu W, Ye J, Liu J, Chen Y, Su H, Young WL and Yang GY: Endothelial progenitor cell transplantation improves long-term stroke outcome in mice. Ann Neurol 67: 488-497, 2010.

27. Yamaguchi J, Kusano KF, Masuo O, Kawamoto A, Silver M, Murasawa S, Bosch-Marce M, Masuda H, Losordo DW, Isner JM and Asahara T: Stromal cell-derived factor-1 effects on ex vivo expanded endothelial progenitor cell recruitment for ischemic neovascularization. Circulation 107: 1322-1328, 2003.

28. Liu ZJ and Velazquez OC: Hyperoxia, endothelial progenitor cell mobilization, and diabetic wound healing. Antioxid Redox Signal 10: 1869-1882, 2008.

29. Dome B, Timar J, Ladanyi A, Paku S, Renyi-Vamos F, Klepetko W, Lang G, Dome P, Bogos K and Tovari J: Circulating endothelial cells, bone marrow-derived endothelial progenitor cells and proangiogenic hematopoietic cells in cancer: From biology to therapy. Crit Rev Oncol Hematol 69: 108-124, 2009.

30. de la Puente P, Muz B, Azab F and Azab AK: Cell trafficking of endothelial progenitor cells in tumor progression. Clin Cancer Res 19: 3360-3368, 2013

31. Tazzyman S, Lewis CE and Murdoch C: Neutrophils: Key mediators of tumour angiogenesis. Int J Exp Pathol 90: 222-231, 2009.

32. Folkman J: Role of angiogenesis in tumor growth and metastasis Semin Oncol 29 (6 Suppl 16): S15-S18, 2002.

33. Rak J, Filmus J and Kerbel RS: Reciprocal paracrine interactions between tumour cells and endothelial cells: The 'angiogenesis progression' hypothesis. Eur J Cancer 32A: 2438-2450, 1996

34. Folkman J: Angiogenesis-dependent diseases. Semin Oncol 28: 536-542, 2001

35. Folkman J: Angiogenesis and apoptosis. Semin Cancer Biol 13: $159-167,2003$

36. Fidler IJ and Ellis LM: The implications of angiogenesis for the biology and therapy of cancer metastasis. Cell 79: 185-188, 1994

37. Urbich C and Dimmeler S: Endothelial progenitor cells: Characterization and role in vascular biology. Circ Res 95: 343-353, 2004

38. Li Calzi S, Neu MB, Shaw LC, Kielczewski JL, Moldovan NI and Grant MB: EPCs and pathological angiogenesis: When good cells go bad. Microvasc Res 79: 207-216, 2010.

39. Xu XH, Pan W, Kang LH, Feng H and Song YQ: Association of annexin A2 with cancer development (Review). Oncol Rep 33: 2121-2128, 2015.

40. Urbich C, Aicher A, Heeschen C, Dernbach E, Hofmann WK, Zeiher AM and Dimmeler S: Soluble factors released by endothelial progenitor cells promote migration of endothelial cells and cardiac resident progenitor cells. J Mol Cell Cardiol 39: 733-742, 2005.

41. Lyden D, Hattori K, Dias S, Costa C, Blaikie P, Butros L, Chadburn A, Heissig B, Marks W, Witte L, et al: Impaired recruitment of bone-marrow-derived endothelial and hematopoietic precursor cells blocks tumor angiogenesis and growth. Nat Med 7: 1194-1201, 2001

42. Hristov $\mathrm{M}$ and Weber C: Endothelial progenitor cells: Characterization, pathophysiology, and possible clinical relevance. J Cell Mol Med 8: 498-508, 2004

43. Hristov M, Erl W and Weber PC: Endothelial progenitor cells: Isolation and characterization. Trends Cardiovasc Med 13 201-206, 2003

44. Stoll BR, Migliorini C, Kadambi A, Munn LL and Jain RK: A mathematical model of the contribution of endothelial progenitor cells to angiogenesis in tumors: Implications for antiangiogenic therapy. Blood 102: 2555-2561, 2003.

45. Nozawa $\mathrm{H}$, Chiu $\mathrm{C}$ and Hanahan D: Infiltrating neutrophils mediate the initial angiogenic switch in a mouse model of multistage carcinogenesis. Proc Natl Acad Sci USA 103: 12493-12498, 2006.

46. Shojaei F, Wu X, Malik AK, Zhong C, Baldwin ME, Schanz S, Fuh G, Gerber HP and Ferrara N: Tumor refractoriness to anti-VEGF treatment is mediated by $\mathrm{CD}_{11} \mathrm{~b}^{+} \mathrm{Grl}^{+}$myeloid cells . Nat Biotechnol 25: 911-920, 2007.

47. Li DW, Liu ZQ, Wei J, Liu Y and Hu LS: Contribution of endothelial progenitor cells to neovascularization (Review). Int J Mol Med 30: 1000-1006, 2012.
48. Lapidot T and Petit I: Current understanding of stem cell mobilization: The roles of chemokines, proteolytic enzymes, adhesion molecules, cytokines and stromal cells. Exp Hematol 30: 973-981, 2002

49. Lapidot T, Dar A and Kollet O: How do stem cells find their way home? Blood 106: 1901-1910, 2005.

50. Ferrara N and Alitalo K: Clinical applications of angiogenic growth factors and their inhibitors. Nat Med 5: 1359-1364, 1999.

51. Asahara T, Takahashi T, Masuda H, Kalka C, Chen D, Iwaguro H, Inai Y, Silver M, Isner JM, et al: VEGF contributes to postnatal neovascularization by mobilizing bone marrow-derived endothelial progenitor cells. EMBO J 18: 3964-3972, 1999.

52. Kalka C, Masuda H, Takahashi T, Gordon R, Tepper O, Gravereaux E, Pieczek A, Iwaguro H, Hayashi SI, Isner JM and Asahara T: Vascular endothelial growth factor(165) gene transfer augments circulating endothelial progenitor cells in human subjects. Circ Res 86: 1198-1202, 2000.

53. Hattori K, Dias S, Heissig B, Hackett NR, Lyden D, Tateno M, Hicklin DJ, Zhu Z, Witte L, Crystal RG, et al: Vascular endothelial growth factor and angiopoietin-1 stimulate postnatal hematopoiesis by recruitment of vasculogenic and hematopoietic stem cells. J Exp Med 193: 1005-1014, 2001.

54. Kopp HG, Ramos CA and Rafii S: Contribution of endothelial progenitors and proangiogenic hematopoietic cells to vascularization of tumor and ischemic tissue. Curr Opin Hematol 13: 175-181, 2006.

55. Kopp HG, Avecilla ST, Hooper AT and Rafii S: The bone marrow vascular niche: Home of HSC differentiation and mobilization. Physiology (Bethesda) 20: 349-356, 2005.

56. Heissig B, Hattori K, Dias S, Friedrich M, Ferris B, Hackett NR, Crystal RG, Besmer P, Lyden D, Moore MA, et al: Recruitment of stem and progenitor cells from the bone marrow niche requires MMP-9 mediated release of kit-ligand. Cell 109: 625-637, 2002.

57. Powell TM, Paul JD, Hill JM, Thompson M, Benjamin M, Rodrigo M, McCoy JP, Read EJ, Khuu HM, Leitman SF, et al: Granulocyte colony-stimulating factor mobilizes functional endothelial progenitor cells in patients with coronary artery disease. Arterioscler Thromb Vasc Biol 25: 296-301, 2005.

58. Lévesque JP, Takamatsu Y, Nilsson SK, Haylock DN and Simmons PJ: Vascular cell adhesion molecule-1 (CD106) is cleaved by neutrophil proteases in the bone marrow following hematopoietic progenitor cell mobilization by granulocyte colony-stimulating factor. Blood 98: 1289-1297, 2001.

59. Chang EI, Chang EI, Thangarajah H, Hamou C and Gurtner GC: Hypoxia, hormones, and endothelial progenitor cells in hemangioma. Lymphat Res Biol 5: 237-243, 2007.

60. Ling CC, Ng KT, Shao Y, Geng W, Xiao JW, Liu H, Li CX, Liu XB, Ma YY, Yeung WH, et al: Post-transplant endothelial progenitor cell mobilization via CXCL10/CXCR3 signaling promotes liver tumor growth. J Hepatol 60: 103-109, 2014.

61. Spring H, Schüler T, Arnold B, Hämmerling GJ and Ganss R: Chemokines direct endothelial progenitors into tumor neovessels. Proc Natl Acad Sci USA 102: 18111-18116, 2005.

62. Shibata R, Skurk C, Ouchi N, Galasso G, Kondo K, Ohashi T, Shimano M, Kihara S, Murohara T and Walsh K: Adiponectin promotes endothelial progenitor cell number and function. FEBS Lett 582: 1607-1612, 2008.

63. Nakamura N, Naruse K, Matsuki T, Hamada Y, Nakashima E, Kamiya H, Matsubara T, Enomoto A, Takahashi M, Oiso Y and Nakamura J: Adiponectin promotes migration activities of endothelial progenitor cells via Cdc42/Rac1. FEBS Lett 583 : 2457-2463, 2009.

64. Landskroner-Eiger S, Qian B, Muise ES, Nawrocki AR, Berger JP, Fine EJ, Koba W, Deng Y, Pollard JW and Scherer PE: Proangiogenic contribution of adiponectin toward mammary tumor growth in vivo. Clin Cancer Res 15 3265-3276, 2009.

65. Kucia M, Reca R, Miekus K, Wanzeck J, Wojakowski W, Janowska-Wieczorek A, Ratajczak J and Ratajczak MZ: Trafficking of normal stem cells and metastasis of cancer stem cells involve similar mechanisms: Pivotal role of the SDF-1-CXCR4 axis. Stem Cells 23: 879-894, 2005.

66. Ceradini DJ, Kulkarni AR, Callaghan MJ, Tepper OM, Bastidas N, Kleinman ME, Capla JM, Galiano RD, Levine JP and Gurtner GC: Progenitor cell trafficking is regulated by hypoxic gradients through HIF-1 induction of SDF-1. Nat Med 10: 858-864, 2004.

67. Bhakta S, Hong P and Koc O: The surface adhesion molecule CXCR4 stimulates mesenchymal stem cell migration to stromal cell-derived factor-1 in vitro but does not decrease apoptosis under serum deprivation. Cardiovasc Revasc Med 7: 19-24, 2006 . 
68. Kryczek I, Lange A, Mottram P, Alvarez X, Cheng P, Hogan M, Moons L, Wei S, Zou L, Machelon V, et al: CXCL12 and vascular endothelial growth factor synergistically induce neoangiogenesis in human ovarian cancers. Cancer Res 65: 465-472, 2005.

69. Darash-Yahana M, Pikarsky E, Abramovitch R, Zeira E, Pal B, Karplus R, Beider K, Avniel S, Kasem S, Galun E and Peled A: Role of high expression levels of CXCR4 in tumor growth, vascularization and metastasis. FASEB J 18: 1240-1242, 2004.

70. Pugh CW and Ratcliffe PJ: Regulation of angiogenesis by hypoxia: role of the HIF system. Nat Med 9: 677-684, 2003.

71. Kollet O, Shivtiel S, Chen YQ, Suriawinata J, Thung SN, Dabeva MD, Kahn J, Spiegel A, Dar A, Samira S, et al: HGF, SDF-1, and MMP-9 are involved in stress-induced human CD34 stem cell recruitment to the liver. J Clin Invest 112: 160-169, 2003.

72. Askari AT, Unzek S, Popovic ZB, Goldman CK, Forudi F, Kiedrowski M, Rovner A, Ellis SG, Thomas JD, DiCorleto PE, et al: Effect of stromal-cell-derived factor 1 on stem-cell homing and tissue regeneration in ischaemic cardiomyopathy. Lancet 362 : 697-703, 2003

73. Arbab AS, Janic B, Knight RA, Anderson SA, Pawelczyk E, Rad AM, Read EJ, Pandit SD and Frank JA: Detection of migration of locally implanted $\mathrm{AC} 33^{+}$stem cells by cellular magnetic resonance imaging with histological findings. FASEB J 22: 3234-3246, 2008.

74. Gallagher KA, Liu ZJ, Xiao M, Chen H, Goldstein LJ, Buerk DG, Nedeau A, Thom SR and Velazquez OC: Diabetic impairments in NO-mediated endothelial progenitor cell mobilization and homing are reversed by hyperoxia and SDF-1 alpha. J Clin Invest 117: 1249-1259, 2007.

75. Abbott JD, Huang Y, Liu D, Hickey R, Krause DS and Giordano FJ: Stromal cell-derived factor-1alpha plays a critical role in stem cell recruitment to the heart after myocardial infarction but is not sufficient to induce homing in the absence of injury. Circulation 110: 3300-3305, 2004.

76. Walter DH, Haendeler J, Reinhold J, Rochwalsky U, Seeger F Honold J, Hoffmann J, Urbich C, Lehmann R, Arenzana-Seisdesdos F, et al: Impaired CXCR4 signaling contributes to the reduced neovascularization capacity of endothelial progenitor cells from patients with coronary artery disease. Circ Res 97 $1142-1151,2005$

77. Sun X, Cheng G, Hao M, Zheng J, Zhou X, Zhang J, Taichman RS, Pienta KJ and Wang J: CXCL12/CXCR4/CXCR7 chemokine axis and cancer progression. Cancer Metastasis Rev 29: 709-722, 2010.

78. Vajkoczy P, Blum S, Lamparter M, Mailhammer R, Erber R, Engelhardt B, Vestweber D and Hatzopoulos AK: Multistep nature of microvascular recruitment of ex vivo-expanded embryonic endothelial progenitor cells during tumor angiogenesis. J Exp Med 197: 1755-1765, 2003.

79. Di Santo S, Diehm N, Ortmann J, Völzmann J, Yang Z, Keo HH, Baumgartner I and Kalka C: Oxidized low density lipoprotein impairs endothelial progenitor cell function by downregulation of E-selectin and integrin alpha(v)beta5. Biochem Biophys Res Commun 373: 528-532, 2008.

80. Lapidot T: Mechanism of human stem cell migration and repopulation of NOD/SCID and B2mnull NOD/SCID mice. The role of SDF-1/CXCR4 interactions. Ann N Y Acad Sci 938: 83-95, 2001.

81. Chavakis E, Aicher A, Heeschen C, Sasaki K, Kaiser R, El Makhfi N, Urbich C, Peters T, Scharffetter-Kochanek K, Zeiher AM, et al: Role of beta2-integrins for homing and neovascularization capacity of endothelial progenitor cells. J Exp Med 201: 63-72, 2005.
82. Carmona G, Chavakis E, Koehl U, Zeiher AM and Dimmeler S: Activation of Epac stimulates integrin-dependent homing of progenitor cells. Blood 111: 2640-2646, 2008.

83. Bauters C, Marotte F, Hamon M, Oliviéro P, Farhadian F, Robert V, Samuel JL and Rappaport L: Accumulation of fetal fibronectin mRNAs after balloon denudation of rabbit arteries. Circulation 92: 904-911, 1995.

84. Chavakis E, Hain A, Vinci M, Carmona G, Bianchi ME, Vajkoczy P, Zeiher AM, Chavakis T and Dimmeler S: High-mobility group box 1 activates integrin-dependent homing of endothelial progenitor cells. Circ Res 100: 204-212, 2007.

85. Caiado F and Dias S: Endothelial progenitor cells and integrins: Adhesive needs. Fibrogenesis Tissue Repair 5: 4, 2012.

86. Hanjaya-Putra D, Yee J, Ceci D, Truitt R, Yee D and Gerecht S: Vascular endothelial growth factor and substrate mechanics regulate in vitro tubulogenesis of endothelial progenitor cells J Cell Mol Med 14: 2436-2447, 2010.

87. Jin H, Aiyer A, Su J, Borgstrom P, Stupack D, Friedlander M and Varner J: A homing mechanism for bone marrow-derived progenitor cell recruitment to the neovasculature. J Clin Invest 116: 652-662, 2006.

88. Qin G, Ii M, Silver M, Wecker A, Bord E, Ma H, Gavin M, Goukassian DA, Yoon YS, Papayannopoulou T, et al: Functional disruption of alpha4 integrin mobilizes bone marrow-derived endothelial progenitors and augments ischemic neovascularization. J Exp Med 203: 153-163, 2006.

89. Hall K and Ran S: Regulation of tumor angiogenesis by the local environment. Front Biosci (Landmark Ed) 15: 195-212, 2010.

90. McKeage MJ and Baguley BC: Disrupting established tumor blood vessels: An emerging therapeutic strategy for cancer. Cancer 116: 1859-1871, 2010

91. Folkman J: Tumor angiogenesis: Therapeutic implications. N Engl J Med 285: 1182-1186, 1971.

92. Ribatti D, Vacca A and Dammacco F: The role of the vascular phase in solid tumor growth: A historical review. Neoplasia 1: 293-302, 1999.

93. Tosetti F, Ferrari N, De Flora S and Albini A: Angioprevention': Angiogenesis is a common and key target for cancer chemopreventive agents. FASEB J 16: 2-14, 2002.

94. Albini A, Noonan DM and Ferrari N: Molecular pathways for cancer angioprevention. Clin Cancer Res 13: 4320-4325, 2007.

95. Li WW, Li VW, Hutnik M and Chiou AS: Tumor angiogenesis as a target for dietary cancer prevention. J Oncol 2012: 879623 , 2012.

96. Zhao YH, Yuan B, Chen J, Feng DH, Zhao B, Qin C and Chen YF: Endothelial progenitor cells: Therapeutic perspective for ischemic stroke. CNS Neurosci Ther 19: 67-75, 2013.

97. Peters BA, Diaz LA, Polyak K, Meszler L, Romans K, Guinan EC, Antin JH, Myerson D, Hamilton SR, Vogelstein B, et al: Contribution of bone marrow-derived endothelial cells to human tumor vasculature. Nat Med 11: 261-262, 2005

98. Murakami J, Li TS, Ueda K, Tanaka T and Hamano K: Inhibition of accelerated tumor growth by blocking the recruitment of mobilized endothelial progenitor cells after chemotherapy. Int J Cancer 124: 1685-1692, 2009. 